\title{
CARACTERIZAÇÃO DE ACESSOS DE BATATA-DOCE BASEADO EM CARACTERÍSTICAS MORFOLÓGICAS
}

\section{Monique Moreira Moulin}

Doutora em Genética e Melhoramento de Plantas/Instituto Federal do Espírito Santo moniquemoulin@gmail.com (Autora correspondente)

\section{Cintia dos Santos Bento}

Doutora em Genética e Melhoramento de Plantas/Universidade Estadual do Norte Fluminense Darcy Ribeiro

cdossantosbento@hotmail.com

\section{Alexandre Cristiano Santos Júnior}

Mestre em Ciências de Alimentos/Instituto Federal do Espírito Santo acsjunior@ifes.edu.br

\section{Rosana Rodrigues}

Doutora em Produção Vegetal/Universidade Estadual do Norte Fluminense Darcy Ribeiro anadiguess@hotmail.com

\section{RESUMO}

A batata-doce possui grande potencial econômico e nutricional, sendo de grande relevância para a geração de renda de agricultores familiares. Neste contexto, a caracterização deste recurso genético deve ser prioridade em programas de melhoramento da olerícola. Os agricultores tradicionais do município de Campos dos Goytacazes e São João da Barra detêm genótipos de batata-doce com expressiva diversidade genética em suas propriedades. O presente trabalho objetivou coletar raízes e ramas de batata-doce em propriedades rurais e estabelecimentos comerciais da região Norte do Estado do Rio de Janeiro, caracterizar os acessos coletados com base em marcadores morfoagronômicos e estimar a divergência genética da população estudada. Para os dados quantitativos de raiz foi utilizada a Distância Euclidiana Média, obtendo-se a matriz de dissimilaridade, e o agrupamento foi realizado com auxílio do método de agrupamento das divergências médias (UPGMA). Observou-se variação para os dez caracteres qualitativos de raiz avaliados, confirmando a alta variabilidade fenotípica dos genótipos de batata-doce estudados. Não foi detectada correlação entre as distâncias geográficas e as distâncias genéticas mensuradas pelo índice de dissimilaridade de Jaccard, configurando uma ausência de estruturação entre a variabilidade genética e o local de coleta, o que pode ser explicado pelo método de propagação assexuado e à prática de constantes trocas entre os produtores rurais da região. A caracterização morfoagronômica quantitativa e qualitativa foi eficiente para estimar a diversidade genética existente entre os acessos de batata-doce cultivados e comercializados na região norte do estado do Rio de Janeiro.

Palavras-chave: Variabilidade genética; Recursos Genéticos; Descritores Morfológicos. 


\section{ABSTRACT}

The sweet potato has great economic and nutritional potential, being of great relevance for the income generation of farmers. In this context, the characterization of this genetic resource should be a priority in vegetable crop breeding programs. The traditional farmers of Campos dos Goytacazes and São João da Barra have been maintaining sweet potato genotypes with expressive genetic diversity in their properties. The present work aimed to collect sweet potato roots and stems from farms and markets located in North of Rio de Janeiro State; to characterize the collected accessions using morphological agronomic, and to estimate the genetic divergence of studied population. For roots quantitative data, Mean Euclidian Distance was used to obtain the dissimilarity matrix and also UPGMA was used to cluster the accessions. Variation among ten roots quantitative traits, confirming the large phenotypic variability of sweet potato in this study. Moreover, no correlation between geographic and genetic distances was detected, based on Jaccard Index, demonstrating that there was no relationship between genetic variability and the exact location where each accession was collected. This can be explained by the usual vegetative propagation of sweet potato and also by the germplasm exchange among farmers, a common practice in the sampled region. The quantitative and qualitative morphoagronomic was efficient to evaluate the genetic diversity among the accessions of sweet potato grown and marketed in the northern region of the state of Rio de Janeiro.

Keywords: Genetic variability, Genetic Resources, Morphological Descriptors.

\section{INTRODUÇÃO}

A batata-doce (Ipomoea batatas L.) pertence à família Convolvulaceae, que agrupa mais de 1000 espécies, sendo ela a única espécie de valor comercial(Jones, 1967). A variabilidade dentro da espécie é muito alta, provavelmente relacionado ao alto nível de ploidia $(2 n=6 x=90)$. O Brasil é conhecido por ser um dos centros secundários da espécie. (Ritschel et al., 1999).

No Brasil, a batata-doce é cultivada principalmente pelos pequenos agricultores, sendo considerada uma cultura bastante antiga e utilizada como alimento base pelas populações de baixa renda. Mais recentemente, tem sido considerada uma alternativa para produção de etanol. $\mathrm{O}$ processo de destilação de álcool a partir do amido da batata-doce pode produzir de 170 a 200 litros de álcool por tonelada da raiz, em razão do seu teor de açúcares (Silveira, 2007). O cultivo utiliza pouca tecnologia e, em geral, os produtores não têm a devida orientação profissional, resultando em baixos índices de produtividade no país (Zero e Lima, 2005).

A batata-doce possui um alto valor nutritivo, sendo um alimento energético devido ao elevado teor de amido. Fornece quantidades consideráveis de sais minerais, principalmente cálcio, ferro e de vitaminas do complexo B e C, além de vitamina $\mathrm{E}$, essencial para a saúde da pele. Algumas cultivares são ricas em carotenóides (Nascimento et al., 2013). As fibras desse vegetal, concentradas especialmente na casca, ajudam a baixar o colesterol e melhorar a digestão (Guedes, 2004).

Uma das características relevantes da espécie é a elevada variabilidade fenotípica e genotípica, o que lhe confere adaptabilidade a diferentes condições edafoclimáticas (Mantovani et al., 2013). Normalmente, essa cultura se adapta bem a regiões de clima tropical e subtropical, com grande luminosidade e chuvas bem distribuídas (Cavalcante et al., 2009). A planta é considerada uma cultura rústica, pois apresenta grande resistência a pragas, boa resposta à aplicação de fertilizantes, desenvolvendo-se em solos de baixa fertilidade e até degradados. Devido à sua rusticidade, poucas são as pesquisas realizadas com esta cultura no Brasil (Mantovani et al., 2013).

Persp. online: biol. \& saúde, Campos dos Goytacazes, 13 (4), 23-36, 2014

seer.perspectivasonline.com.br 
O conhecimento da diversidade genética presente entre os acessos tem grande importância para o manejo e uso do germoplasma nos programas de melhoramento genético das espécies (Sobral et al., 2012). Segundo Neitzke et al. (2010) o incremento das atividades de coleta, caracterização e avaliação do germoplasma deve ser prioridade entre as estratégias de abordagem e manejo dos recursos genéticos no Brasil. O germoplasma conservado serve como um reservatório de genes, os quais os melhoristas podem acessar quando precisam melhorar características específicas, tal como a resistência a uma doença. Faria et al. (2013) destacam que superadas as deficiências de informação, o germoplasma será mais útil para os programas de melhoramento.

A caracterização morfológica de acessos de um banco de germoplasma é normalmente a forma mais acessível de quantificar sua diversidade genética (Spooner et al., 2005), sendo que alguns relatos para batata-doce encontram-se disponíveis na literatura (Daros et al., 2002; Ritschel e Huamán, 2002; Veasey et al., 2007; Cavalcante et al., 2009; Moulin et al., 2012).

No Brasil, a prática do cultivo de variedades locais de batata-doce está intrinsecamente ligada ao contexto cultural relacionado ao modo de vida das famílias, e ao conhecimento tradicional associado. Nesse sentido, a agricultura familiar tem assegurado o uso de práticas de conservação de diversas variedades locais de batata-doce, uma vez que mantém o cultivo bem como detem conhecimento tradicional associado a este (Albagli e Maciel, 2003). Para que haja conhecimento do germoplasma mantido pelos agricultores tradicionais e compreensão da importância econômica e social exercida pela cultura, são necessárias ações que estabeleçam coleta dos recursos genéticos junto aos produtores rurais e geração de informações relativas à caracterização dos acessos.

As atividades relacionadas aos recursos genéticos (coleta, caracterização, multiplicação, documentação e conservação) assumem fundamental importância para otimizar o uso imediato desses recursos em programas de melhoramento genético. Neste contexto, torna-se fundamental realizar a conservação adequada das coleções e a sua caracterização, visando estimar a variabilidade real mantida, de forma a disponibilizar o material conservado para utilização efetiva pelos agricultores (Cabral et al., 2010) e para a pesquisa.

O presente trabalho teve por objetivo caracterizar, com base em descritores morfoagronômicos, e estimar a divergência genética de acessos de batata-doce coletados em propriedades rurais e estabelecimentos comerciais da região Norte do Estado do Rio de Janeiro.

\section{METODOLOGIA}

\subsection{Coleta dos acessos}

As raízes de batata-doce foram coletadas em 21 propriedades rurais e dezesseis mercados e feiras localizadas na região Norte Fluminense, nos municípios de Campos dos Goytacazes e São João da Barra, totalizando 27 acessos coletados em propriedades rurais e 19 obtidos em estabelecimentos comerciais, resultando em 46 acessos coletados. Nas propriedades rurais que o produtor não dispunha de raízes, devido ao estágio jovem de desenvolvimento da olerícola, eram coletadas ramas jovens, ao invés das raízes.

Quanto às raízes, foram coletadas aquelas completamente desenvolvidas e firmes, sendo obtidas no mínimo três raízes de cada acesso junto aos produtores rurais. As raízes receberam uma numeração UENF e foram mantidas nas condições de laboratório até que houvesse brotações. $\mathrm{O}$ transplantio foi efetuado quando as raízes possuíam brotações que apresentavem entre três e quatro folhas. Raízes e ramas foram levadas para casa-de-vegetação, na Unidade de Apoio à Pesquisa (UAP), área experimental da Universidade Estadual do Norte Fluminense Darcy Ribeiro (UENF), onde foram cultivadas inicialmente em vasos de 5 litros e posteriormente transferidas para as condições de campo. A caracterização morfoagronômica foi realizada em campo e no Laboratório de Recursos Genéticos da UENF. 
As plantas foram conduzidas em condições de campo seguindo as recomendações de Filgueira (2005) para o manejo da cultura da batata-doce. As plantas foram cultivadas com solo tratado, e posteriormente, após 90 dias de plantio foi efetuada a caracterização morfológica de três raízes de cada acesso.

\subsection{Caracterização morfológica das raízes coletadas}

Os acessos foram caracterizados por descritores morfoagronômicos específicos para batatadoce, que estão disponíveis em Bioversity International (Descriptors for sweet potato), propostos por Huamán (1991). Foram utilizados dez descritores, sendo cinco para caracteres quantitativos e cinco para aspectos qualitativos de raiz. Os caracteres qualitativos foram avaliados por quatro pessoas, por envolver uma percepção subjetiva, contribuindo para uma classificação fenotípica mais apurada. Os descritores de raiz foram:

a) Peso da raiz (g) - obtido com o uso de balança digital;

b) Comprimento da raiz $(\mathrm{cm})$ - mensurado o maior comprimento, de uma extremidade a outra, obtido com o uso do paquímetro digital;

c) Diâmetro da raiz $(\mathrm{cm})$ - obtido através da medição da região de maior diâmetro, com uso do paquímetro digital;

d) Espessura do córtex - o córtex foi mensurado na região de maior diâmetro da raiz, determinado por meio de uma escala de notas, com utilização do paquímetro digital: 1 muito fina $(<1 \mathrm{~mm}) ; 3$ - fina $(1-2 \mathrm{~mm}) ; 5$ - intermediária $(2-3 \mathrm{~mm}) ; 7$ - espessa $(3-4 \mathrm{~mm})$; e, 9 - muito espessa $(>4 \mathrm{~mm})$;

e) Teor de Sólidos Solúveis Totais $\left({ }^{\circ}\right.$ Brix $)$ - determinado com auxílio de refratômetro digital com amostras do suco extraído da raiz. Pedaços das raízes foram processados e posteriormente coados para obtenção do suco;

f) Formato das raízes - determinado por meio de uma escala de notas: 1 - redonda; 2 redonda elíptica; 3 - elíptica; 4 - oval; 5 - oboval; 6 - oblonga; 7 - oblonga longa; 8 - longa elíptica; e, 9 - longa irregular ou com curvaturas;

g) Defeitos de superfície - determinado por meio de uma escala de notas: 0 - ausente; 1 - pele semelhante a jacaré; 2 - veias; 3 - constrições horizontais superficiais; 4 - constrições horizontais profundas; 5 - fendas horizontais superficiais; 6 - fendas horizontais profundas; e, 7 - constrições e fendas profundas;

h) Cor da pele - determinado visualmente por meio de uma escala de notas: 1 - branca; 2 creme; 3 - amarela; 4 - laranja; 5 - marrom alaranjado; 6 - rosa; 7 - vermelha; 8 vermelha arroxeada; e, 9 - roxa escura;

i) Intensidade da cor da pele - determinado por meio de uma escala de notas: 1 - pálida; 2 intermediária; e, 3 - escura;

j) Cor da polpa - determinado visualmente por meio de uma escala de notas: 1 - branca; 2 creme; 3 - creme escura; 4 - amarelo pálida 5 - amarelo-escura 6 - laranja pálida; 7 laranja intermediária; 8 - laranja escura; e, 9 - pigmentado fortemente com antocianinas.

\subsection{Análise estatística}

Os dados quantitativos das raízes foram analisados com auxílio do programa Genes (Cruz, 2006) para obtenção da matriz de dissimilaridade e pelo programa $R$ (http://www.r-project.org) para obtenção do dendrograma.

A estimativa da matriz de distância genética por meio das variáveis quantitativas foi obtida com base na distância Euclidiana Média Padronizada. O agrupamento das raízes foi obtido pelo método Unweighted Paired Group Method using Arithmetic averages (UPGMA) e a validação pelo coeficiente de correlação cofenético. 
Para os dados qualitativos, adotou-se uma metodologia de análise descritiva em percentual da frequência das classes fenotípicas, onde cada uma das classes de formato da raiz, defeitos de superfície, cor da pele, intensidade da cor da pele e cor da polpa da batata-doce foram representadas em gráficos, com seus respectivos percentuais.

\section{RESULTADOS E DISCUSSÃO}

\subsection{Análise quantitativa}

Constatou-se alta variabilidade genética para todos os caracteres quantitativos radiculares estudados, sendo obtidos valores bastante discrepantes, o que ressalta a ampla divergência entre os acessos coletados. O peso das raízes variou de 46,7 a 869,8 g. O comprimento variou de 7,7 a 21,7 $\mathrm{cm}$. Resultados similares foram obtidos por Cavalcante et al. (2003), constatando diferença significativa entre os genótipos para comprimento da raiz, com comprimento máximo de $20,8 \mathrm{~cm}$. Para o diâmetro foram obtidos valores entre 5,2 e 13,6 cm. Cavalcante et al. (2009) encontraram uma menor variabilidade para esta característica variando de 5,0 a 6,7 cm. Entretanto, estes autores caracterizaram apenas 11 acessos de batata-doce. Para espessura do córtex foram encontrados valores que variaram de 0,07 a 0,6 mm. A variável BRIX (teor de sólidos solúveis) demonstrou valores entre 5,2 e $25,0^{\circ} \mathrm{BRIX}$.

Para os dados analisados, foi obtida a análise de variância (Tabela 1), na qual foi detectado um elevado desvio padrão para o peso da raiz $(22,79)$. Para a matriz de correlação cofenética (Tabela 2), o caráter peso das raízes correlacionou-se positivamente com o comprimento da raiz $(0,614)$, diâmetro da raiz $(0,178)$ e espessura do córtex da raiz $(0,180)$. O caráter comprimento da raiz foi negativamente correlacionado com diâmetro da raiz $(-0,623)$ e espessura do córtex $(-0,372)$, e positivamente correlacionado com o teor de sólidos solúveis $(0,243)$. Para diâmetro da raiz a correlação foi positiva com o caráter espessura do córtex e negativa com o teor de sólidos solúveis. Entre a espessura do córtex e o teor de sólidos solúveis foi obtida uma correlação negativa.

Tabela 1. Valores de média, desvio padrão, mínimo e máximo dos 46 acessos de batata-doce adquiridos em estabelecimentos comerciais e propriedades rurais na região Norte do Estado do Rio de Janeiro.

\begin{tabular}{lllllll}
\hline Estatística & $\begin{array}{l}\text { Peso da raiz } \\
(\mathrm{g})\end{array}$ & $\begin{array}{l}\text { Comprimento } \\
\text { da raiz }(\mathrm{cm})\end{array}$ & $\begin{array}{l}\text { Diâmetro } \\
\text { raiz }(\mathrm{cm})\end{array}$ & $\begin{array}{l}\text { Espessura do } \\
\text { córtex }(\mathrm{mm})\end{array}$ & $\begin{array}{l}\text { Teor de } \\
\text { Solúveis } \\
\left({ }^{\circ} \text { brix }\right)\end{array}$ & $\begin{array}{l}\text { Sólidos } \\
\text { Totais }\end{array}$ \\
\hline Média & 302,28 & 15,25 & 8,64 & 0,18 & 11,02 \\
Desvio Padrão & 22,79 & 1,08 & 0,43 & 0,45 & 3,26 \\
Mín. & 46,70 & 7,71 & 5,20 & 0,07 & 5,20 \\
Máx. & 869,82 & 21,07 & 13,60 & 0,6 & 25,00 \\
\hline
\end{tabular}

Persp. online: biol. \& saúde, Campos dos Goytacazes, 13 (4), 23-36, 2014

seer.perspectivasonline.com.br 
Tabela 2: Matriz de correlação fenotípica obtida com base em descritores quantitativos radiculares, entre 46 acessos de batata-doce adquiridos em estabelecimentos comerciais e propriedades rurais na região Norte do Estado do Rio de Janeiro.

\begin{tabular}{llllll}
\hline Tratamento & $\begin{array}{l}\text { Peso } \\
\text { raiz }\end{array}$ & $\begin{array}{l}\text { da } \\
\text { da raiz }\end{array}$ & $\begin{array}{l}\text { Diâmetro } \\
\text { raiz }\end{array}$ & $\begin{array}{l}\text { da } \\
\text { Espessura } \\
\text { do córtex }\end{array}$ & $\begin{array}{l}\text { Teor de Sólidos } \\
\text { Solúveis Totais }\end{array}$ \\
\hline Peso da raiz & $0,614^{* *}$ & $0,178^{* *}$ & $0,180^{* *}$ & 0,096 \\
$\begin{array}{l}\text { Comprimento } \\
\text { da raiz }\end{array}$ & & $-0,623^{* *}$ & $-0,372^{* *}$ & $0,243^{* *}$ \\
$\begin{array}{l}\text { Diâmetro da } \\
\text { raiz }\end{array}$ & & & $0,620^{* *}$ & $-0,201^{* *}$ \\
$\begin{array}{l}\text { Espessura do } \\
\text { córtex }\end{array}$ & & & $-0,166^{*}$ \\
Teor & & & \\
Sólidos de & & & & \\
Solúveis & & & & \\
Totais & & & & \\
\hline
\end{tabular}

*** Significativo a 1 e $5 \%$ de probabilidade, respectivamente.

A técnica UPGMA foi eficiente no ajuste entre as distâncias, com correlação cofenética de 0,83 para as associações entre a matriz de correlação fenotípica e o dendrograma das variáveis quantitativas. Estima-se que houve um bom ajuste entre as distâncias, pois de acordo com Sokal e Rohlfe (1995), o ajuste adequado é avaliado pelos valores de correlação cofenética superiores a 0,80. O agrupamento dos acessos representado pelo dendrograma, Figura 1, permitiu distinguir cinco grupos, sendo para tanto, realizado um corte a uma distância de 1,3.

O grupo I, constituído pelo acessos UENF 1942, foi caracterizado pelo genótipo com maior teor de sólidos solúveis totais (25,0 ${ }^{\circ}$ BRIX), o que é muito interessante para a comercialização, devido ao sabor mais doce da polpa, e para a indústria de produção de etanol. O grupo II compreendeu o maior número de acessos, correspondendo a 36 acessos ou 78,2 \% do total. Este grupo foi dividido em dois subgrupos. O subgrupo II.A (acessos UENF 1954, UENF 1947, UENF 1968, UENF 1930, UENF 1935, UENF 1936, UENF 1969, UENF 1940, UENF 1943) foi caracterizado por acessos com os maiores comprimentos (variando de 11,5 a 21,7 cm), pesos médios (121,6 a 179,5 g) e diâmetros menores (5,7 a 8,2 cm). No subgrupo II.B (acessos UENF 1934, UENF 1944, UENF 1949, UENF 1939, UENF 1945, UENF 1982, UENF 1933, UENF 1948, UENF 1985, UENF 1984, UENF 1963, UENF 1950, UENF 1937, UENF 1925, UENF 1956, UENF 1972, UENF 1923, UENF 1920, UENF 1964, UENF 1917, UENF 1924, UENF 1952, UENF 1958, UENF 1926, UENF 1922, UENF 1932 e UENF 1953) foi observado acessos de pesos médios (154,2 a 260,6 g), comprimentos intermediários (11,9 a 16,7 cm), e BRIX mais baixos (média de $\left.8,8^{\circ} \mathrm{BRIX}\right)$.

O grupo III, constituído por UENF 1946, UENF 1955, UENF 1938, UENF 1959, UENF 1974, UENF 1941 e UENF 1951, foi discriminado pelos acessos de pesos elevados (313,1 a 489,8 $\mathrm{g})$, maiores diâmetros $(8,1$ a $12,4 \mathrm{~cm})$, espessura do córtex variável $(0,09$ a $0,3 \mathrm{~mm})$. O grupo IV foi formado por apenas um acesso (UENF 1931), que foi obtido em estabelecimento comercial e proveniente do município de Campos dos Goytacazes. Este acesso se diferenciou dos demais por possuir maior média de diâmetro $(11,6 \mathrm{~cm})$ e espessura do córtex $(0,5 \mathrm{~mm})$. No grupo $\mathrm{V}$ ficou alocado um único acesso (UENF 1967), e neste foi encontrado o clone com maior peso (869,8 g), e menor teor de sólidos solúveis totais $\left(5,2^{\circ} \mathrm{BRIX}\right)$. A média de peso para o grupo foi de $702,3 \mathrm{~g}$.

Todas as características estudadas contribuíram para a dissimilaridade genética da população estudada. O peso e o teor de sólidos solúveis foram importantes para a diferenciação dos grupos,

Persp. online: biol. \& saúde, Campos dos Goytacazes, 13 (4), 23-36, 2014 
enquanto que a espessura do córtex foi à característica que menos contribuiu para a divergência.

Através desses resultados, pode-se confirmar a alta variabilidade fenotípica dos genótipos de batata-doce coletados em propriedades rurais, feiras e estabelecimentos comerciais do município de Campos dos Goytacazes, uma vez que para todas as características quantitativas estudadas foi obtida uma grande amplitude de valores. Resultados obtidos por Queiroga et al. (2007) e Cavalcante et al. (2009) na avaliação de características quantitativas demonstraram significativa variabilidade fenotípica, corroborando com os resultados obtidos na presente pesquisa. 


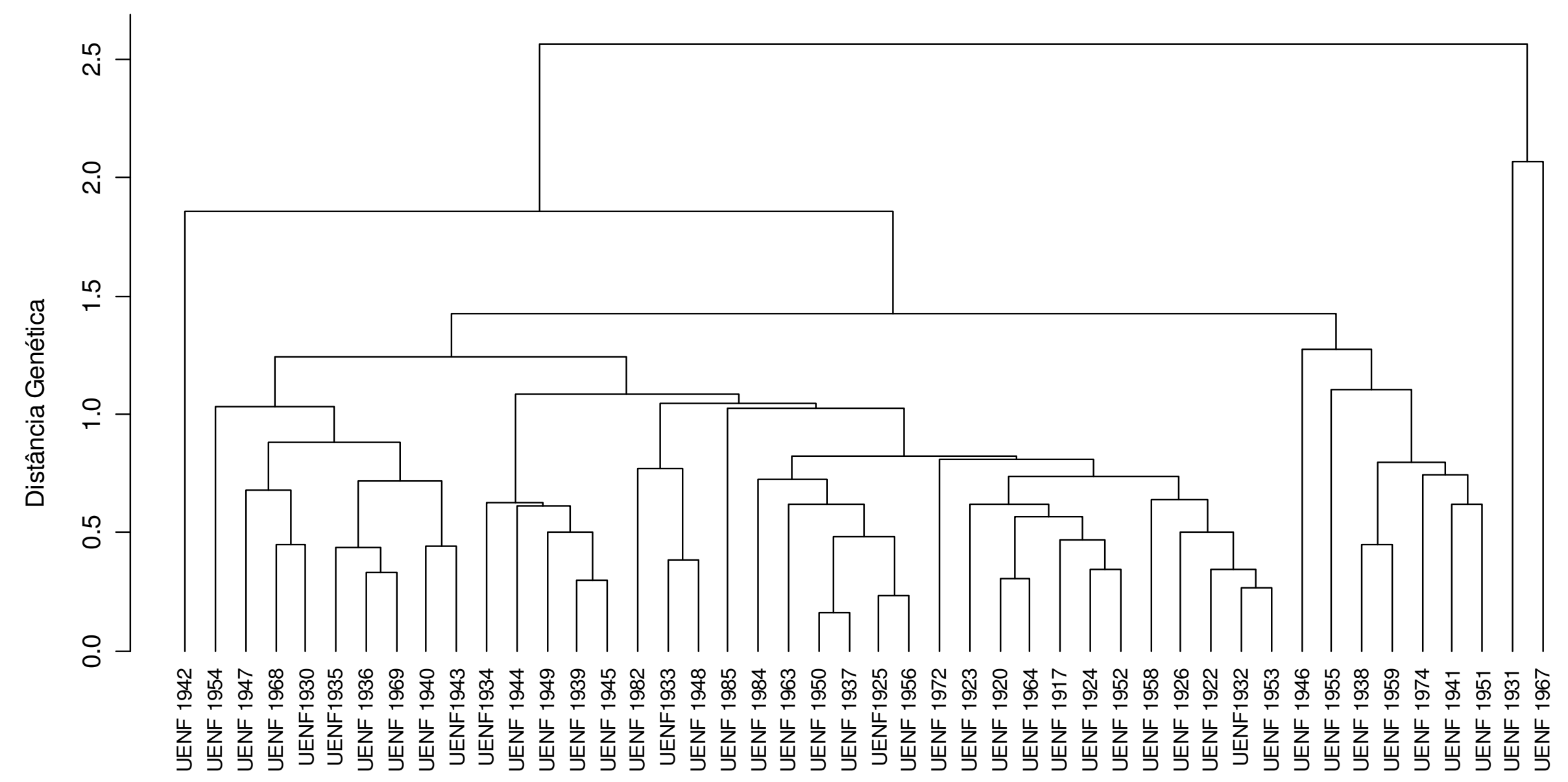

Figura 1: Dendrograma de dissimilaridade genética, obtido pelo método hierárquico de médias ponderadas, com base em descritores quantitativos radiculares, entre 46 acessos de batata-doce adquiridos em estabelecimentos comerciais e propriedades rurais na região Norte do Estado do Rio de Janeiro. 


\subsection{Análise qualitativa}

Com relação às características qualitativas, para o formato das raízes, foi constatada uma grande variabilidade, apresentando sete variações (Figura 2): redonda $(8,7 \%)$, redonda elíptica $(2,2$ $\%$ ), oval $(19,6 \%)$, oboval $(4,3 \%)$, oblonga longa (2,2\%), longa elíptica $(6,5 \%)$ e longa irregular $(56,5 \%)$. Ritschel e Huamán (2002) encontraram oito classes fenotípicas, com predominância dos acessos classificados como longo elíptico $(42,5 \%)$ e irregular $(24,1 \%)$, entretanto nenhum dos acessos avaliados possuía formato oval. Camargo (2013) encontrou predominância de raízes longas elípticas (25\%), oblongas longas (22,5\%) e longas irregulares $(20 \%)$.

Para a variável defeitos da superfície foram observadas raízes sem defeitos $(67,4 \%)$, com pele de jacaré $(2,2 \%)$, com defeitos tipo veia $(17,4 \%)$, constrições horizontais superficiais $(2,2 \%)$, e fendas horizontais superficiais $(8,7 \%)$. Resultados similares foram obtidos por Daros et al. (2002) e Cavalcante (2008), que observaram todas as classes descritas neste trabalho em distintas proporções.

A cor predominante da pele da raiz dos acessos caracterizados foi classificada como rosa $(84,8 \%)$, constatando-se ainda as colorações creme $(10,8 \%)$, marrom alaranjado $(2,2 \%)$, e roxa escura (2,2 \%). Daros et al. (2002) encontraram a cor rosada como predominante (50\%). Entretanto, Chávez et al (2006), Veasey et al. (2007) e Camargo (2013), observaram predominância da coloração creme, enquanto Ritschel e Huamám (2002) classificaram a cor da pele como sendo branca para 41,2 \% dos acessos, e a segunda maior frequência foi para a coloração rosada, representada por $28,6 \%$ dos acessos estudados.

A intensidade da cor da pele foi caracterizada como pálida para 19,6\% dos acessos, intermediária para 43,4 \% e escura para $37 \%$. Da mesma forma, Daros et al. (2002) e Cavalcante (2008) encontraram todas as intensidades para cor da pele da raiz, com predominância da intensidade intermediária.

Para a característica coloração da polpa da raiz foi detectada uma baixa variabilidade, 93,5 $\%$ dos acessos apresentaram polpa de cor creme e 6,5 \% cor da polpa branca. Ritschel e Huamán (2002) encontraram predominância da cor creme em 75,1 \% do germoplasma avaliado. Veasey et al. (2007) caracterizaram $73 \%$ dos genótipos com cor da polpa creme. Chávez et al. (2006) constataram uma grande diversidade de cores para polpa, mas com predominância da cor creme, em consonância com este trabalho e dos demais autores citados. Camargo (2013) encontrou uma maior variação para cor predominante da polpa, foram obtidas seis classes fenotípicas, sendo que a maioria apresentava polpa creme $(37,5 \%)$ e branca $(27,5 \%)$. 

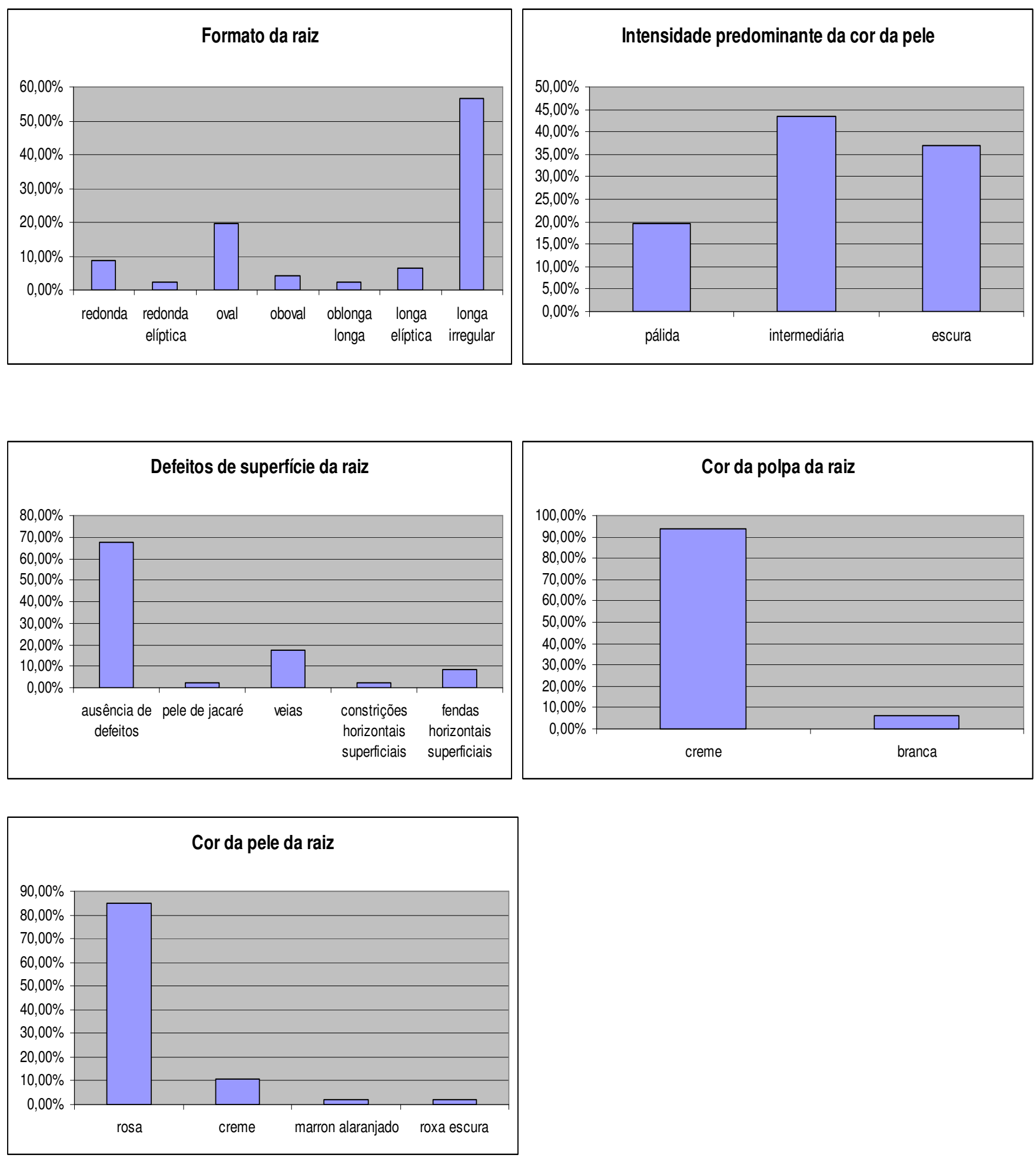

Figura 2: Classes fenotípicas dos descritores para raiz e frequências observadas para os 46 acessos de Ipomoea batatas.

De forma geral, a cor da pele e o formato das raízes foram as características com maior variabilidade, podendo ser considerado um importante descritor no agrupamento dos acessos, contribuindo com significativa diferenciação dos grupos. Estas variáveis também foram as 
principais responsáveis pela divergência genética nos resultados encontrados por Oliveira et al. (2000) e Cavalcante et al. (2009). Por outro lado, Veasey et al. (2007) descrevem como os fatores que mais contribuíram para diversidade a coloração secundária da polpa, formato das raízes e defeitos de superfície da raiz. Para o presente estudo as características que menos contribuíram para o estudo da diversidade genética foram coloração da polpa e cor secundária da polpa da raiz, 93,5\% dos acessos tinham polpa de cor creme e 76,1 \% não possuíam cor secundária da polpa.

Foi constatada uma elevada variabilidade fenotípica para a cor e formato da raiz, sendo obtidas inúmeras classes fenotípicas para esses marcadores (Figura 3). Destaca-se também que raízes coletadas em uma mesma localidade ou localidades muito próximas tiveram alta variabilidade fenotípica, o que evidencia o cultivo de diferentes variedades tradicionais de batatadoce pelos produtores rurais da região norte do Estado do Rio de Janeiro.
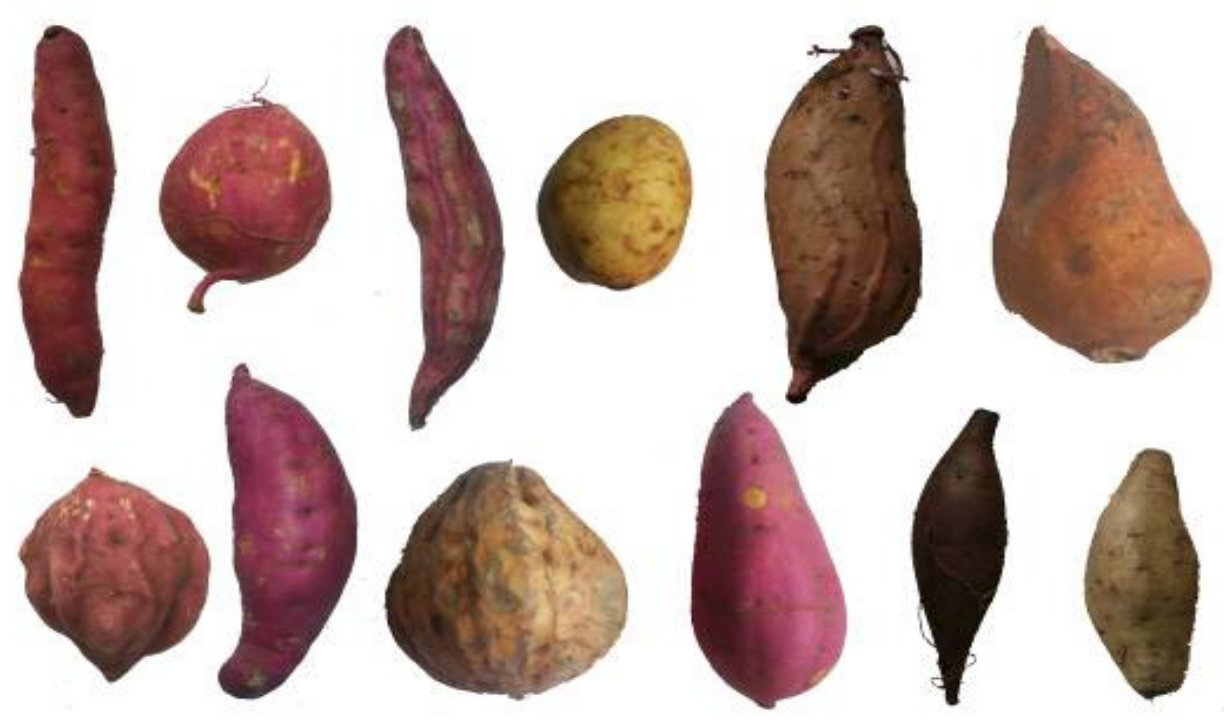

Figura 3: Variabilidade fenotípica para cor e formato dos acessos de batata-doce coletados em propriedades rurais e estabelecimentos comerciais do Norte do Estado do Rio de Janeiro.

Não foi observada correlação entre distância genética e distância geográfica, o que pode ser reflexo da prática comum de trocas de batata-doce entre os produtores rurais ou da de mutações somáticas espontâneas, configurando uma ampla variabilidade mantida pelos agricultores tradicionais da região Norte Fluminense. Foi implantada uma coleção de germoplasma de batatadoce na UENF composta por 46 acessos.

\section{CONCLUSÕES}

A caracterização morfoagronômica quantitativa e qualitativa foi eficiente para estimar a diversidade genética existente entre os acessos de batata-doce cultivados e comercializados na região norte do Estado do Rio de Janeiro.

\section{AGRADECIMENTOS}

A FAPERJ, pela concessão de auxílio e bolsa para desenvolvimento do trabalho.

Persp. online: biol. \& saúde, Campos dos Goytacazes, 13 (4), 23-36, 2014 


\section{REFERÊNCIAS}

ALBAGLI, S., MACIEL, M.L. Informação e conhecimento na inovação e no desenvolvimento local. Ciência da Informação, Brasília. Vol. 33, p. 9-16, 2004.

CABRAL, P. D. S.; SOARES, T. C. B.; GONÇALVES, L. S. A.; AMARAL JÚNIOR, A. T.; LIMA, A. B. P.; RODRIGUES, R.; MATTA, F.P. Quantification of the diversity among common bean accessions using Ward-MLM strategy. Pesquisa Agropecuária Brasileira. Vol. 45, p. 1124-1132, 2010.

CAMARGO, C.K.P. Caracterização de acessos de batata-doce do banco de germoplasma da Unicentro, PR. Tese em Produção Vegetal, Universidade Federal do Paraná, 2013.

CAVALCANTE, M.; FERREIRA, P.V.; PAIXÃO, S.L.; COSTA, J.G.; DA, PEREIRA, R.G.; MADALENA, J.A.S. Potenciais produtivo e genético de clones de batata-doce. Acta Scientiarum. Vol. 31, p. 421-426, 2009.

CAVALCANTE, M. Caracterização morfológica, desempenho produtivo e divergência genética de genótipos de batata-doce. Dissertação de mestrado - Universidade Federal de Alagoas. 61p, 2008.

CAVALCANTE, J.T.; FERREIRA, P.V.; SOARES, L. Avaliação de clones de batata-doce (Ipomoea batatas (L.) Lam.), em Rio Largo - Alagoas. Magistra, Cruz das Almas. Vol. 15, p. 13-17, 2003.

CHÁVEZ, R.; SÁNCHEZ, T.; IGLESIAS, C.C. Caracterización morfológica y molecular de genótipos mejorados de camote (Ipomoea batatas) para ecosistemas Árido-Salino-Bórico. Ciência e Desarrollo. Vol. 8, p. 84-115, 2006.

CRUZ, C.D. Programa GENES: estatística experimental e matrizes. Viçosa: UFV. 285p. 2006.

DAROS, M.; AMARAL JR., A.T.; PEREIRA, T.N.S.; LEAL, N.R.; FREITAS, S.P.; SEDIYAMA, T. Caracterização morfológica de acessos de batata-doce. Horticultura Brasileira. Vol. 20, p. 43-47, 2002.

FARIA, P. N; LAIA, G. A; CARDOSO, K. A; FINGER, F. L; CECON, P. R. Estudo da variabilidade genética de amostras de pimenta (Capsicum chinense Jacq.) existentes num banco de germoplasma: um caso de estudo. Revista de Ciências Agrárias, v. 36, n. 1, p. 17-22, 2013.

FILGUEIRA, F.A.R. Novo manual de olericultura: agrotecnologia moderna na produção e comercialização de hortaliças. Viçosa: UFV, 2005. 412p.

GUEDES, M.C. do. Antocianinas: pigmento natural ou remédio? Revista Científica do IMAPES, p. 71-73, 2004. 
JONES, A. Should Nishiyama's $\mathrm{K}_{123}$ (Ipomoea trifida) be designated I. Batatas? Econ. Bot. Vol. 21, p. 163-166, 1967.

HUAMÁN, Z. Descriptors for sweet potato. Rome: International Board for Genetic Resources/Centro Inter- nacional de la Papa/Asian Vegetable Research and Development Center, 134 p., 1991.

MANTOVANI, E.C.; DELAZARI, F.T.; DIAS, L.E.; ASSIS, I.R.; VIEIRA, G. H. S.; LANDIM, F. M. Eficiência no uso da água de duas cultivares de batata-doce em resposta a diferentes lâminas de irrigação. Horticultura Brasileira. Vol. 31, p. 602-606, 2013.

MOULIN, M. M.; RODRIGUES, R.; GONÇALVES, L. S. A.; SUDRÉ, C. P.; GONZAGA, M. P. A comparison of RAPD and ISSR markers reveals genetic diversity among sweet potato landraces (Ipomoea batatas (L.) Lam). Acta Scientiarum. Vol. 34, p. 139-147, 2012.

NASCIMENTO, K.O; ROCHA, D.G. C.M.; SILVA, E.B.; BARBOSA JÚNIOR, J.L.; BARBOSA, M.I.M.J.; NASCIMENTO, C.O. Caracterização química e informação nutricional de fécula de batata-doce (Ipomoea batatas L.) orgânica e biofortificada. Revista Verde Mossoró, Vol. 8, p. 132-138, 2013.

NEITZKE, R. S.; BARBIERI, R. L.; RODRIGUES, W. F.; CORREAA, I.V.; CARVALHO, F.I.F. Dissimilaridade genética entre acessos de pimenta com potencial ornamental. Horticultura Brasileira, v. 28, n. 4, p. 47-53, 2010.

OLIVEIRA, A.C.B.; SEDIYAMA, M.A.N.; SEDIYAMA, T.; CRUZ, C.D. Avaliação da divergência genética em batata-doce por procedimentos multivariados. Acta Scientiarum. Vol. 22, p. 895-900, 2000.

QUEIROGA, R. C. F.; SANTOS, M. A.; MENEZES, M. A.; VIEIRA, C. P. G.; SILVA, M. C. Fisiologia e produção de cultivares de batata-doce em função da época de colheita. Horticultura Brasileira. Vol. 25, p. 371-374, 2007.

RITSCHEL, P. S.; HUAMÁN, Z.; LOPES, C. A.; MENÊZES, J. E.; TORRES, A. C. Catálogo de germoplasma de batata-doce: Coleção mantida pela Embrapa Hortaliças. Brasília: EMBRAPA - CNPH, 47 p, 1999.

RITSCHEL, P.S., HUAMÁN, Z. Variabilidade morfológica da coleção de germoplasma de batata-doce da Embrapa-Centro Nacional de Pesquisas de Hortaliças. Pesquisa agropecuária brasileira, Brasília. Vol. 37, p. 485-492, 2002.

SILVEIRA, M.A.; ANDRÉ, C.M.; ALVIM, T.C.; DIAS, L.E.; TAVARES, I.B.; SANTANA, A.W.R.; SOUZA, F.R. A cultura da batata-doce como fonte de matéria prima para produção de etanol. Palmas, UFT, 45p., 2007.

SOBRAL, K. M. B.; RAMOS, S. R. R.; GONÇALVES, L. S. A.; AMARAL JÚNIOR, A. T.; ARAGÃO, W. M. Variabilidade genética entre acessos de coqueiro-anão utilizando técnicas de análise multivariada. Magistra, Vol. 24, p. 348-359, 2012.

Persp. online: biol. \& saúde, Campos dos Goytacazes, 13 (4), 23-36, 2014

seer.perspectivasonline.com.br 
SOKAL, R. R.; ROHLF, F. J. Biometry: The principles and practice of statistics in biological research. WH Freeman and Company. New York. USA, $3^{\circ}$ edição, 1995.

SPOONER, D.; VAN TREUREN, R.; DE VICENTE, M.C. Molecular markers for genebank management. IPGRI. Technical Bulletin $\mathrm{n}^{\mathbf{0}} 10$. Disponível em: www.ipgri.cgiar.org/publications/pdf/1082.pdf. International Plant Genetic Resources Institute. Rome, Italy, 2005. Acesso em: 22 de novembro de 2013.

VEASEY, E.A.; SILVA, J. R. Q. DE.; ROSA, M. S.; BORGES, A.; BRESSAN, E.A. DE; PERONI, N. Phenology and morphological diversity of sweet potato (Ipomoea batatas) landraces of the Vale do Ribeira. Scientia Agrícola, Piracicaba. Vol. 64, p. 416-427, 2007.

ZERO. V.M.; LIMA, S.L. DE. Manejo e Produtividade da batata-doce (Ipomoea batatas) no Município de Presidente Prudente - SP. Energia Agrícola., Botucatu. Vol. 20, p. 94-117, 2005. 